\title{
Symptomatic seizures in preterm newborns: a review on clinical features and prognosis
}

\author{
Carlotta Spagnoli', Raffaele Falsaperla ${ }^{2 *}$ (D) Michela Deolmi ${ }^{3}$, Giovanni Corsello ${ }^{4}$ and Francesco Pisani ${ }^{5}$
}

\begin{abstract}
Neonatal seizures are the most common neurological event in newborns, showing higher prevalence in preterm than in full-term infants. In the majority of cases they represent acute symptomatic phenomena, the main etiologies being intraventricular haemorrhage, hypoxic-ischemic encephalopathy, central nervous system infections and transient metabolic derangements.

Current definition of neonatal seizures requires detection of paroxysmal EEG-changes, and in preterm newborns the incidence of electrographic-only seizures seems to be particularly high, further stressing the crucial role of electroencephalogram monitoring in this population. Imaging work-up includes an integration of serial cranial ultrasound and brain magnetic resonance at term-equivalent age. Unfavourable outcomes following seizures in preterm infants include death, neurodevelopmental impairment, epilepsy, cerebral palsy, hearing and visual impairment. As experimental evidence suggests a detrimental role of seizures per se in determining subsequent outcome, they should be promptly treated with the aim to reduce seizure burden and long-term disabilities. However, neonatal seizures show low response to conventional anticonvulsant drugs, and this is even more evident in preterm newborns, due to intrinsic developmental factors. As a consequence, as literature does not provide any specific guidelines, due to the lack of robust evidence, off-label medications are often administered in clinical practice.
\end{abstract}

Keywords: Seizures, Newborn, Outcome, Prognosis, Treatment

\section{Background}

Owing to improved neonatal care strategies and implemented medical technology, the number of surviving preterm newborns is increasing, even among extremely low birth weight babies, although their morbidity rate is higher compared to full-term infants [1]. Hence, new challenges for the medical community include the management and treatment of clinical conditions more often affecting preterm infants, including neonatal seizures, which are the most common neurological event in newborns. In fact, there are several characteristics of preterm babies, such as immature central nervous system development, low birth

\footnotetext{
* Correspondence: raffaelefalsaperla@hotmail.com

${ }^{2}$ Neonatal Intensive Care Unit, Santo Bambino Hospital, University Hospital

"Policlinico-Vittorio Emanuele", Via Tindaro 2, 95124 Catania, Italy

Full list of author information is available at the end of the article
}

weight and periventricular leukomalacia, that also represent risk factors for seizures [2]. However, preterm newborns are also more prone to develop severe complications and they are less responsive to treatment with conventional medications because of age-specific pharmacokinetic and pharmacodynamic features [3]. In spite of these differences between preterm and full-term infants, there is no difference in preterm versus full-term treatment strategies in clinical practice, even if literature data suggest that the same treatment might be less effective and more dangerous in preterm than in full-term newborns. As a consequence, second-line or off-label medications use has been increasingly reported. Irrespective of controversies in their management, neonatal seizures treatment is considered very important in order to reduce morbidity, mortality and seizure burden, and to improve the overall outcome in these patients.

(c) The Author(s). 2018 Open Access This article is distributed under the terms of the Creative Commons Attribution 4.0 International License (http://creativecommons.org/licenses/by/4.0/), which permits unrestricted use, distribution, and reproduction in any medium, provided you give appropriate credit to the original author(s) and the source, provide a link to the Creative Commons license, and indicate if changes were made. The Creative Commons Public Domain Dedication waiver (http://creativecommons.org/publicdomain/zero/1.0/) applies to the data made available in this article, unless otherwise stated. 


\section{Epidemiology}

Neonatal seizures affect up to 1.5-3.5/1000 full-term newborns and 10-130/1000 preterm infants [4]. Therefore, the prevalence of seizures in preterm newborns is higher than in full-term ones (22.2\% compared to $0.5 \%)$ [5], even if a recent study found that the incidence of seizures is lower between 30 and 36 weeks of gestational age than in both extremely preterm infants $(<30 w \mathrm{GA})$ and in near-term ones (36-40w GA) [6].

Furthermore, time of seizure onset seems to be different between preterm and full-term newborns: in fact, they tend to occur later in premature infants. In particular, the first suspected seizure is reported at a median age of $27 \mathrm{~h}$ of life in full-term infants and at 14 days in preterm newborns [7]. Moreover, there are some differences according to gestational age: in a recent study mean seizure onset was 14.6 days (range $1-120$ days, SD 20.4) in $<29 w G A$ newborns, compared to 5.2 days (range 1-37 days, SD 7.7) in $>29$ wGA ones [8]. In a further research, mean seizure onset was 8.3 days of life in infants with gestational age $\leq$ 29 weeks, while it was earlier (3.2 days) in newborns with a gestational age between 30 and 36 weeks [9]. This is likely due to differing seizure etiologies $[6,8-10]$. In particular, seizures caused by intraventricular haemorrhage usually occur during the first $24 \mathrm{~h}$ of life and many preterm newborns' seizures persist into the third day of life [11]. Especially if associated with parenchymal infarction, seizures are most likely to occur in the latter part of the first week of life. Other etiology of seizure in preterm are represented by hypoxic-ischemic encephalopathy, central nervous system infections and transient metabolic derangements [12].

Moreover, the rate of seizures seems to depend on the method of ascertainment, as the prevalence of clinicallydefined seizures ranges from 0,30 [13] to 57.5 per 1000 births [14] while the prevalence of EEG-detected seizures is $24 \%$ in premature infants [10].

\section{Etiology}

Intraventricular haemorrhage and its complications are the main cause of neonatal seizures in very and extremely preterm newborns $(<32 \mathrm{wGA})[8,10]$, and the risk increases with increasing severity of brain injury (grades III and IV intraventricular haemorrhage) [8, 15-17]. On the other hand, in moderate and late preterm infants the majority of seizures are caused by hypoxic-ischemic encephalopathy [10] which shows $40-60 \%$ prevalence in near-term newborns with seizures $[17,18]$. Additional acquired etiologies include central nervous system or systemic infection (i.e. meningitis, viral meningoencephalitis and sepsis) [8], other acquired brain injuries (subarachnoid haemorrhage, ischemic stroke), trauma, transient metabolic diseases (i.e. hypoglycaemia in low birth weight infants, hypocalcaemia, hypomagnesaemia, sodium imbalance in very low birth weight ones) [12], drug withdrawal or poisoning [20].
Neonatal-onset epilepsies (of genetic origin) and inborn errors of metabolism also need to be considered in the differential diagnosis.

\section{Pathophysiology}

Various risk factors have been associated with seizures in preterm newborns, such as lack of state changes on EEG [21], intraventricular haemorrhage, periventricular leukomalacia, surgery, patent ductus arteriosus, necrotizing enterocolitis, pulmonary diseases or respiratory distress and low birth weight [19]. In particular, low birth weight infants show a 9\% increase in seizure rate for each week decrease in gestational age [19].

However, the main reason why preterm infants are prone to develop seizures is their brain immaturity [22].

Gamma-Aminobutyric acid (GABA) is crucial for neuronal maturation and activity-dependent integration into circuits [23]. Immature neurons arecharacterized by high neuronal chloride concentrations, deriving from the different expression of the NKCC1 versus the KCC2 cationchloride cotransporters in immature versus mature neurons $[24,25]$. This causes GABAergic signaling to be mainly excitatory and driven by $\mathrm{NKCC} 1$ receptors in embryonic and early post-natal life [26]. Afterwards, the GABAergic interneuronal network develops and switches from excitatory to inhibitory. Neurophysiologically, there is a concomitant emergence of more 'continuous' oscillations subsiding the spontaneous activity transients (SATs), recorded in extremely preterm newborns [27].

Between 24 and 32 weeks of gestational age, premyelinating oligodendrocyte progenitor cells are particularly vulnerable to hypoxic-ischemic damage [28], due to the interaction of immature blood flow autoregulation, immature vascular supply and heart-rate dependent cardiac output $[22,29]$. Consequently, white matter injury occurs when other predisposing factors such as infections, inflammations and disturbances in cerebral oxygenation overlap with the intrinsic vulnerability of the premature brain [30]. Oligodendroglial damage causes impaired myelination, while parenchymal haemorrhage or high grade intraventricular haemorrhage cause projection and association fibers injury. When changes affect subplate neurons, both the cortex and its connections with the thalamus are damaged [28], and this can lead to higher long-term cortical excitability [31].

In particular, extremely low birth weight newborns often display a passive cerebral blood flow [32]. As a consequence, the occurrence of intraventricular haemorrhage is more frequent, and various hypotheses have been proposed to explain this higher risk. First of all, some conditions such as pneumothorax, changes in head position and ventilator asynchrony can cause impaired venous drainage, thus facilitating haemorrhage. Second, sudden changes in arterial blood pressure caused by sepsis, noxious stimuli, 
fluid boluses or inotropes can have the same effect, leading to intraventricular haemorrhage [29].

\section{Diagnosis}

Neonatal seizures in newborns are clinically defined as abnormal, stereotyped and paroxysmal dysfunctions in the central nervous system, occurring within 44 weeks of gestational age.

From a clinical point of view, neonatal seizures are divided into clonic, myoclonic, tonic and subtle seizures. Clonic seizures consist of repetitive, rhythmic (1-4/s) contractions of muscle groups of the limbs, face or trunk. They can be focal or multifocal. They are usually electrically-confirmed. Myoclonic seizures are isolated or repetitive contractions of proximal or distal muscles, less regular and persistent than clonic jerks. They can be generalized, focal or multifocal. Tonic seizures are classified as generalized or focal. Focal tonic seizures consist of sustained, but transient, asymmetrical posturing of the trunk or extremities or tonic eye deviation, while generalized tonic seizures are bilateral symmetrical tonic posturing (with flexor/extensor predominance or mixed). Electrographic correlate is inconsistent for both seizure types. Subtle seizures include motor automatisms (such as chewing, swallowing, sucking, repetitive tongue movements, "cycling", "boxing", "pedaling", "swimming") and autonomic signs (changes in heart rate or breathing pattern, flushing, salivation, pupil dilatation) [33].

Neurophysiologically a seizure is defined as the presence of a paroxysmal EEG change with a clear onset and termination, lasting at least $10 \mathrm{~s}$, and an evolution in frequency, morphology and amplitude.

As above said, the prevalence of neonatal seizures is higher in preterm $(22.2 \%)$ than in full-term newborns (0.5\%) [5] but studies about clinically-defined seizures show a larger percentage of neonatal seizures than EEG-based studies [34, 35], especially aEEG-based ones [11, 15]. For example, a prospective study about infants born before the 32nd week of gestational age found a $5 \%$ incidence of neonatal seizures [36]. In contrast, $11.9 \%$ incidence has been reported in studies on clinically-diagnosed seizures [6].

Clinical-only seizures (without any electrographic evidence), are usually considered non-epileptic and related to the loss of cortical inhibition on subcortical structures [37].

Paroxysmal non-epileptic motor phenomena should be taken into consideration in the differential diagnosis [38].

No general consensus has been achieved on the definition of neonatal status epilepticus. A commonly adopted definition considers it as continuous seizure activity lasting $\geq 30 \mathrm{~min}$ or the occurrence of recurrent seizures $\geq 50 \%$ of the recording time $(1-3 \mathrm{~h})$ [18]. For a recent review on controversies regarding status epilepticus, please refer to (Pavlidis, Pisani EJPN 2018) [39].

\section{Monitoring of preterm newborns at increased risk of seizures}

If possible, a multimodal neurophysiological and neuroimaging approach is recommended in newborns [40].

\section{Neurophysiologic monitoring: Conventional and amplitude-integrated EEG}

Literature points out the importance of EEG monitoring in the context of suspected seizures, both for diagnosis and to evaluate treatment efficacy.

Conventional video-EEG enables definition of seizure onset, spread, duration and correlation with motor phenomena. Therefore, it can differentiate paroxysmal nonepileptic motor phenomena (not associated with any EEG changes) and detect electrographic-only seizures [41]. It can give early prognostic information, suggesting etiologies such as a focal injury or a diffuse pathology and indicates severity of functional compromise [34, 38, 42, 43]. In fact, background activity is a strong predictor of outcome, in particular when serial recordings are performed [44]. Moreover, even after seizure confirmation, prolonged or continuous monitoring are useful to quantify "seizure burden" and to diagnose neonatal status epilepticus [45, 46]. EEG-monitoring is required to test anticonvulsants efficacy, so it is recommended to continue EEG-recording for at least $24 \mathrm{~h}$ of seizure freedom [47], and it is also advisable to monitor the newborn after drug discontinuation. In addition, the literature suggests that amplitude-integrated EEG (aEEG) might miss seizures originating far from the electrodes or of short duration. It can also lead to false positive results due to artefacts. Consequently, it is mainly used as a screening tool, while conventional EEG is recorded to improve sensitivity and specificity $[48,49]$. In preterm newborns, the first EEG-recording is recommended as soon as possible after birth, because its sensitivity is higher in the first $48 \mathrm{~h}$ of life [50, 51].

\section{Cranial ultrasound scan}

Another non-invasive and low cost technique to detect seizure etiology is cranial ultrasound scan (CUS). Therefore, a scan protocol for preterm infants has been proposed. In particular, a CUS is always recommended at term equivalent age in preterm newborns and, from the 23rd to the 35th week of GA, a CUS should be performed in the first $24 \mathrm{~h}$ of life, then at the first, second and third week of life. Additional cranial ultrasound scans are recommended depending on gestational age [52]. Moreover, CUS should be integrated with brain magnetic resonance (MRI) at term equivalent age when intraventricular haemorrhage, to detect ventriculomegaly, white matter injury and cerebellar involvement $[53,54]$. 


\section{Brain MRI}

First of all, brain magnetic resonance imaging (MRI) can recognize specific patterns in seizures due to structural causes, for example related to central nervous system infections [55]. Conventional brain MRI should be performed in preterm newborns at term-equivalent age, to gain more accurate information about ventriculomegaly, white matter injury and cerebellar involvement in case of uncomplicated intraventricular haemorrhage [53, 54]. In contrast, when hypoxic-ischemic encephalopathy is the seizures cause, brain injury can be detected earlier with diffusion weighted imaging (DWI), while conventional brain MRI shows a loss of grey-white matter differentiation at the end of the first week of life [56].

\section{Treatment}

According to experimental and clinical data [57], prolonged seizures may contribute to poor neurological outcome, thus they should be promptly treated in an attempt to reduce long-term disabilities [58]. However, therapeutic options for seizures in newborns are still unsatisfactory [59] and the available evidence is poor [60].

Moreover, the literature does not provide any customized treatment approach for premature newborns suffering from neonatal seizures, even if several studies show a lower response rate than in full-term infants, with poorer prognosis. In fact, liver and renal function, but also central nervous system development, are not complete in premature infants, leading to differences in drugs pharmacokinetics and pharmacodynamics. Hence, potentially the same treatment might be both less effective and more dangerous in a preterm newborn than in a full-term one. However, studies found no difference in treatment strategies according to gestational age in clinical practice [61]. Conventional GABAergic antiseizure medications are less effective in newborns, because GABAergic signalling is mainly driven by NKCC1 receptors, with an excitatory instead of inhibitory effect $[24,26]$. As a consequence, second-line or off-label medications are increasingly administered to newborns and proposed in treatment algorithms, although the underlying evidence is low [62]. The recommended first-line choice is represented by phenobarbital in both term and preterm infants (80\% of cases), even if its efficacy is approximately $50 \%$, followed by phenytoin in $40 \%$ of patients. This is based on the availability of randomized controlled safety and efficacy data [63]. In the lack of clear-cut evidence or guidance, when no response is obtained with conventional antiseizure drugs, off-label agents are often administered, such as levetiracetam, topiramate, lidocaine and midazolam. [3, 62, 64, 65]. Studies about pharmacokinetics and pharmacodynamic changes in preterm infants, report a longer half-life and a higher distribution volumes in preterm than in full-term newborns for both first-line and second-line antiseizure medications
[66-69]. Anyway, it is important to notice that in recent years, levetiracetam has been increasingly used for treatment of neonatal seizures. Along with other papers [64, $70-73,74]$, a recent retrospective analysis on preterm infants treated with levetiracetam as first-line showed $57 \%$ of seizure freedom at the end of the first week of life, without requiring any other treatment, no adverse drug reactions or laboratory abnormalities, suggesting that levetiracetam can be a safe option in neonates [75].

Finally, no clear evidence on when to discontinue medications is available, although in the majority of newborns therapy is continued after discharge from neonatal units [10]. A recent perspective research demonstrates that in neonates suffering from hypoxic-ischemic encephalopathy, antiseizure medication discontinuation prior to discharge did not increase the risk of seizures after discharge [75]. A further recent study suggests to use the need for a second antiseizure medication and time to seizure control to determine when to discontinue phenobarbital, supporting its early discontinuation [76].

\section{Outcome and risk factors for unfavourable outcome}

Seizures in preterm newborns result in an increased risk of developing several medical conditions with neurological and intellectual disabilities. Recent papers show that, thanks to innovations in neonatal care, there has been a reduction in mortality, but, as a consequence, an increase in morbidity [77, 78]. In fact, common unfavourable outcomes include epilepsy, cerebral palsy [77], cognitive impairment (intellectual disability and developmental delay, $64 \%$ vs $29 \%$ in preterm infants with seizures compared to those without seizures), microcephaly [79], hearing (11\% vs $4 \%$ in preterm newborns without seizures) and vision impairment (43\% vs $14 \%)$.

Studies detect a normal long-term outcome in a small percentage of patients (12-25\%). In comparison, a normal outcome is more common in both full-term infants suffering from seizures $[18,78,80]$ and in preterm infants without seizures [81].

In accordance with these data, mortality rate is higher in preterm (32-35\%) than in full-term newborns with seizures $(5.4-15 \%)[10,80,82]$ and in preterm infants without seizures $(5-16.6 \%)$ [35, 82]. Risk factors for mortality include birth weight lower than $1000 \mathrm{~g}$, birth at GA $<28$ weeks and severely abnormal background EEG patterns, such as isoelectric or low voltage invariant activity, burst-suppression or permanent discontinuous activity, and longer seizure duration, namely status epilepticus $[8,9]$. In the context of status epilepticus, the mortality risk is higher in preterm compared to full-term newborns (52,6\% versus $17,8 \%$ ), even though, interestingly no statistically significant differences between preterm and full-term infants with status 
epilepticus were documented, except for Apgar scores and neurological examination [46].

Notably, background EEG pattern represents an independent predictor of mortality [8]. When seizures are exclusively subclinical, mortality rate is higher [7], while late death (after 36 weeks of post-menstrual age) and neuro-developmental impairment have been reported as more frequent in patients with clinical seizures [82].

Additional risk factors for poor prognosis include male sex, multiple birth, non-Caucasian newborns, low birth weight [82] and poor response to anticonvulsant drugs [7]. This latter factor has been associated with a higher rate of later epilepsy, together with severely abnormal cranial ultrasound scan and EEG (especially when the ictal activity spreads to the contralateral hemisphere) and status epilepticus [35, 43], as they underline more severe brain injury. In particular, status epilepticus is an independent predictor of unfavourable outcome, because it is associated with subsequent epilepsy in both preterm and full term infants [80]. Studies show that status epilepticus is more frequent in preterm infants with birth weight lower than $1000 \mathrm{~g}$ or between 1500 and 2499 g, with severely abnormal EEG traces and neurological examination $[8,46]$. Anyway, it is important to notice that preterm newborns with status epilepticus show a lower incidence of post-neonatal epilepsy than full-term ones [18], even if still as high as 40 times higher than in the general population [78].

In contrast, cerebral palsy as an outcome in patients suffering from neonatal seizures seems to be higher in preterm infants than in full-term newborns [77], especially when prematurity is associated with periventricular leukomalacia, severe intraventricular haemorrhage, systemic disease or infections [83, 84]. Regarding the administration of steroids in newborns, there seems to be an increased risk of cerebral palsy when they are administered after birth, while the risk is lower if administered in the antenatal period [83].

Furthermore, with respect to intellectual impairment following neonatal seizures, evidence shows a high rate of severe impairment (61\%), with lower percentage of moderate (22\%) and mild (17\%) impairment, without statistically significant differences associated to gestational age [9]. The risk of cognitive impairment seems to be higher in clinically-diagnosed than in EEG-diagnosed seizures $[78,81]$.

\section{Conclusion}

Acute symptomatic neonatal seizures can be caused by several conditions which should be detected because prognosis largely depends on underlying etiology. The most frequent cause in preterm infants is intraventricular haemorrhage. Appropriate clinical and neurophysiologic monitoring, neuroimaging techniques and improvement in neurocritical care in the neonatal period are improving management of infants with seizures, and their outcome, especially mortality risk. However, the occurrence of seizures in preterm newborns is still associated with poor cognitive development, visual, hearing and motor impairment, cerebral palsy and epilepsy. Early treatment should be provided to neonates presenting seizures (even electrical seizures) to reduce mortality and disabilities and to improve long-term outcome especially in very and extremely preterm newborns.

\section{Future perspectives}

In the future, research should be addressed to identify a customized treatment for preterm newborns, considering their pharmacokinetic and pharmacodynamic changes and brain developmental stages. Randomized controlled studies are required in order to establish if treatment strategies should be differentiated according to gestational age and underlying etiology (and how) with special emphasis on treatment duration and timing of treatment discontinuation.

\section{Abbreviations \\ aEEG: Amplitude-integrated electroencephalogram; CUS: Cranial ultrasound scan; DWI: Diffusion weighted imaging; EEG: Electroencephalogram; GA: Gestational age; GABA: Gamma-Aminobutyric acid; MRI: Magnetic resonance imaging; SAT: Spontaneous activity transient; SD: Standard deviation}

\section{Acknowledgements}

Not applicable.

Funding

The authors have no funding source to declare.

\section{Availability of data and materials}

Data sharing not applicable to this article as no datasets were generated or analyzed during the current study.

\section{Authors' contributions}

SC conceived of the study, and participated in its design and coordination and helped to draft the manuscript. RF help to draft the manuscript, DM help to draft the manuscript. GC conceived of the study in its design. FP conceived of the study, and participated in its design and coordination and helped to draft the manuscript. All authors read and approved the final manuscript.

Ethics approval and consent to participate

Not applicable.

\section{Consent for publication}

Not applicable.

\section{Competing interests}

The authors declare that they have no competing interests.

\section{Publisher's Note}

Springer Nature remains neutral with regard to jurisdictional claims in published maps and institutional affiliations.

\section{Author details}

${ }^{1}$ Child Neuropsychiatry Unit, Department of Pediatrics, Arcispedale Santa Maria Nuova, IRCSS, Reggio Emilia, Italy. ${ }^{2}$ Neonatal Intensive Care Unit, Santo Bambino Hospital, University Hospital "Policlinico-Vittorio Emanuele", Via Tindaro 2, 95124 Catania, Italy. ${ }^{3}$ Pediatrics Unit, Medicine \& Surgery 
Department, University of Parma, Parma, Italy. ${ }^{4}$ Department of Maternal and Child Health, University of Palermo, Palermo, Italy. ${ }^{5}$ Child Neuropsychiatry Unit, Medicine \& Surgery Department, Neuroscience Division, University of Parma, Parma, Italy.

\section{Received: 1 August 2018 Accepted: 16 October 2018 Published online: 01 November 2018}

\section{References}

1. Platt MJ. Outcomes in preterm infants. Public Health. 2014;128(5):399-403.

2. Vasudevan C, Levene M. Epidemiology and aetiology of neonatal seizures. Semin Fetal Neonatal Med. 2013;18(4):185-91.

3. Donovan MD, Griffin BT, Kharoshankaya L, Cryan JF, Boylan GB. Pharmacotherapy for neonatal seizures: current knowledge and future perspectives. Drugs. 2016;76(6):647-61.

4. Bassan $H$, Bental Y, Shany E, Berger I, Froom P, Levi L, et al. Neonatal seizures: dilemmas in workup and management. Pediatr Neurol. 2008;38(6):415-21.

5. Scher MS. Neonatal seizure classification: a fetal perspective concerning childhood epilepsy. Epilepsy Res. 2006;70(Suppl 1):S41-57.

6. Sheth RD, Hobbs GR, Mullett M. Neonatal seizures: incidence, onset, and etiology by gestational age. J Perinatol. 1999;19:40-3.

7. Glass HC, Shellhaas RA, Wusthoff CJ, Chang T, Abend NS, Chu CJ, et al. Neonatal Seizure Registry study group. Contemporary profile of Seizures in Neonates: A Prospective Cohort Study. J Pediatr. 2016;174:98-103.el.

8. Pisani F, Facini C, Pelosi A, Mazzotta S, Spagnoli C, Pavlidis E. Neonatal seizures in preterm newborns: a predictive model for outcome. Eur J Paediatr Neurol. 2016;20:243-51.

9. Pisani F, Barilli AM, Sisti L, Bevilacqua G, Seri S. Preterm infants with videoEEG confirmed seizures. Outcome at 30 months of age. Brain and Development. 2008:30:20-30.

10. Glass HC, Shellhaas RA, Tsuchida TN, Chang T, Wusthoff CJ, Chu CJ, et al. Neonatal seizure registry study group. Seizures in preterm neonates: a multicenter observational cohort study. Pediatr Neurol. 2017;72:19-24.

11. Vesoulis ZA, Inder TE, Woodward L, Buse B, Vavasseur C, Mathur AM. Early electrographic seizures, brain injury, and neurodevelopmental risk in the very preterm infant. Pediatr Res. 2014;75:564-9.

12. Vasudevan C, Levene M. Epidemiology and aetiology of neonatal seizures. Semin Fetal Neonatal Med. 2013;18:185-91.

13. Berry K, Pesko MF, Hesdorffer DC, Shellhaas RA, Seirup JK, Grinspan ZM. An evaluation of national birth certificate data for neonatal seizure epidemiology. Epilepsia. 2017 Mar;58(3):446-55.

14. Lanska MJ, Lanska DJ. Neonatal seizures in the United States: results of the National Hospital Discharge Survey, 1980-1991. Neuroepidemiology. 1996; 15:117-25

15. Shah DK, Zempel J, Barton T, Lukas K, Inder TE. Electrographic seizures in preterm infants during the first week of life are associated with cerebral injury. Pediatr Res. 2010;67:102-6.

16. Wikstrom S, Ley D, Hansen-Pupp I, Rosén I, Hellström-Westas L. Early amplitude-integrated EEG correlates with cord TNF-alpha and brain injury in very preterm infants. Acta Paediatr. 2008;97:915-9.

17. Volpe JJ. Neurology of the Newborn. 5th ed. Philadelphia: Saunders/Elsevier; 2008.

18. Scher MS, Aso K, Beggarly ME, Hamid MY, Steppe DA, Painter MJ. Electrographic seizures in preterm and full-term neonates: clinical correlates, associated brain lesions, and risk for neurologic sequelae. Pediatrics. 1993;91:128-34.

19. Kohelet D, Shochat R, Lusky A, Reichman B. Israel Neonatal Network Risk factors for neonatal seizures in very low birth weight infants: populationbased survey. J Child Neurol. 2004;19:123-8.

20. Shellhaas R. Etiology and prognosis of neonatal seizures. 2017. https://www. uptodate.com/contents/etiology-and-prognosis-of-neonatal-seizures. Accessed 27 June 2018. UpToDate,

21. Buraniqi E, Sansevere AJ, Kapur K, Bergin AM, Pearl PL, Loddenkemper T. Electrographic seizures in preterm neonates in the neonatal intensive care unit. J Child Neurol. 2017;32:880-5.

22. Volpe JJ. Brain injury in premature infants: a complex amalgam of destructive and developmental disturbances. Lancet Neurol. 2009:8:110-24.

23. Ben-Ari Y. Excitatory actions of gaba during development: the nature of the nurture. Nat Rev Neurosci. 2002;3:728-39.

24. Rivera C, Voipio J, Payne JA, Ruusuvuori E, Lahtinen H, Lamsa K, et al. The K +/Cl- co-transporter KCC2 renders GABA hyperpolarizing during neuronal maturation. Nature. 1999;397:251-5.
25. Plotkin MD, Snyder EY, Hebert SC, Delpire E. Expression of the Na-K-2Cl cotransporter is developmentally regulated in postnatal rat brains: a possible mechanism underlying GABA's excitatory role in immature brain. J Neurobiol. 1997:33:781-95.

26. Wang DD, Kriegstein AR. Blocking early GABA depolarization with bumetanide results in permanent alterations in cortical circuits and sensorimotor gating deficits. Cereb Cortex. 2011;21:574-87.

27. Vanhatalo S, Palva JM, Andersson S, Rivera C, Voipio J, Kaila K. Slow endogenous activity transients and developmental expression of $\mathrm{KCl}$ cotransporter 2 in the immature human cortex. Eur J Neurosci. 2005;22:2799e804

28. McQuillen PS, Sheldon RA, Shatz CJ, Ferriero DM. Selective vulnerability of subplate neurons after early neonatal hypoxiaischemia. J Neurosci. 2003;23: 3308-15.

29. Vesoulis ZA, Mathur AM. Cerebral autoregulation, brain injury, and the transitioning premature infant. Front Pediatr. 2017:5:64.

30. Kidokoro H, Anderson PJ, Doyle LW, Woodward LJ, Neil JJ, Inder TE. Brain injury and altered brain growth in preterm infants: predictors and prognosis. Pediatrics. 2014;134:e444-53.

31. Lein ES, Finney EM, McQuillen PS, Shatz CJ. Subplate neuron ablation alters neurotrophin expression and ocular dominance column formation. Proc Natl Acad Sci U S A. 1999:96:13491-5.

32. Soul JS, Hammer PE, Tsuji M, Saul JP, Bassan H, Limperopoulos C, et al. Fluctuating pressure-passivity is common in the cerebral circulation of sick premature infants. Pediatr Res. 2007;61:467-73.

33. Fisher RS, Cross JH, French JA, Higurashi N, Hirsch E, Jansen FE, et al. Operational classification of seizure types by the international league against epilepsy: position paper of the ILAE Commission for Classification and Terminology. Epilepsia. 2017;58(4):522-30.

34. Okumura A, Hayakawa F, Kato T, Itomi K, Maruyama K, Kubota T, et al. Icta electroencephalographic findings of neonatal seizures in preterm infants. Brain and Development. 2008;30:261-8.

35. Pisani F, Copioli C, Turco EC, Sisti L, Cossu G, Seri S. Mortality risk after neonatal seizures in very preterm newborns. J Child Neurol. 2012;27:1264-9.

36. Lloyd RO, O'Toole JM, Pavlidis E, Filan PM, Boylan GB. Electrographic Seizures during the Early Postnatal Period in Preterm Infants. J Pediatr. 2017; 187:18-25.e2.

37. Mizrahi EM, Kellaway P. Characterization and classification of neonatal seizures. Neurology. 1987:37:1837-44.

38. Orivoli S, Facini C, Pisani F. Paroxysmal nonepileptic motor phenomena in newborn. Brain and Development. 2015;37:833-9.

39. Pisani F, Pavlidis E. What is new: talk about status epilepticus in the neonatal period. EJPN. 2018. https://doi.org/10.1016/j.ejpn.2018.05.009.

40. Pisani F, Spagnoli C. Monitoring of newborns at risk for brain injury. Ital J Pediatr. 2016:42:48.

41. Murray DM, Boylan GB, Ali I, Ryan CA, Murphy BP, Connolly S. Defining the gap between electrographic seizure burden, clinical expression and staff recognition of neonatal seizures. Arch Dis Child Fetal Neonatal Ed. 2008;3. https://doi.org/10.1136/adc.2005.086314.

42. Patrizi S, Holmes GL, Orzalesi M, Allemand F. Neonatal seizures: characteristics of EEG ictal activity in preterm and fullterm infants. Brain and Development. 2003:25:427-37.

43. Pisani F, Copioli C, Di Gioia C, Turco E, Sisti L. Neonatal seizures: relation of ictal video-electroencephalography (EEG) findings with neurodevelopmental outcome. J Child Neurol. 2008;23:394-8.

44. Shelhaas RA, Chang T, Tsuchida T, Secher MS, Riviello JJ, Abend NS, et al. The American clinical neurophysiology society's guidelines on continuous elctroencephalography monitoring in neonates. J Clin Neurophysiol. 2011;28:611-7.

45. Lawrence R, Inder T. Neonatal status epilepticus. Semin Pediatr Neurol. 2010; 17(3):163-8.

46. Pavlidis E, Spagnoli C, Pelosi A, Mazzotta S, Pisani F. Neonatal status epilepticus: differences between preterm and term newborn. Eur J Paediatr Neurol. 2015;19:314-9.

47. Scher MS, Alvin J, Gaus L, Minnigh B, Painter MJ. Uncoupling of EEG-clinical neonatal seizures after antiepileptic drug use. Pediatr Neurol. 2003;28:277-80.

48. Abend NS, Wusthoff CJ. Neonatal seizures and status epilepticus. J Clin Neurophysiol. 2012;29:441-8

49. Shah DK, Mackay MT, Lavery S, Watson S, Harvey AS, Zempel J, et al. Accuracy of bedside electroencephalographic monitoring in comparison with simultaneous continuous electroencephalography for seizure detection in term infants. Pediatrics. 2008;121:1146-54. 
50. Kidokoro $\mathrm{H}$. Chronologic changes in neonatal EEG findings in periventricular leukomalacia. Pediatrics. 2009;124(3):e468-75.

51. Maruyama K, Okumura A, Hayakawa F, Kato T, Kubta T, Kuno K, et al. Prognostic value of EEG depression in preterm infants for later development of cerebral palsy. Neuropediatrics. 2002;33:133-7.

52. Leijser LM, de Vries LS, Cowan FM. Using cerebal ultrasound effectively in the newborn infant. Early Hum Dev. 2006;82:827-35.

53. De Vries LS, Benders MJ, Groenendaal F. Imaging the premature brain: ultrasound or MRI? Neuroradiology. 2013;55:13-22.

54. Kwon SH, Vasung L, Ment LR, Huppi PS. The role of neuroimaging in predicting neurodevelopmental outcomes of preterm neonates. Clin Perinatol. 2014;41:257-83.

55. Weeke LC, Groenendaal F, Toet MC, Benders MJ, Nievelstein RA, van Rooij $L G$, et al. The aetiology of neonatal seizures and the diagnostic contribution of neonatal cerebral magnetic resonance imaging. Dev Med Child Neurol. 2015:57:248-56.

56. Bednarek N, Mathur A, Inder T, Wilkinson J, Neil J, Shimony J. Impact of therapeutic hypothermia on MRI diffusion changes in neonatal encephalopathy. Neurology. 2012;78:1420-7.

57. Clancy RR. Prolonged electroencephalogram monitoring for seizures and their treatment. Clin Perinatol. 2006;33(3):649-65.

58. Silverstein FS, Jensen FE. Neonatal seizures. Ann Neurol. 2007;62(2):112-20.

59. Spagnoli C, Pavlidis E, Pisani F. Neonatal seizures therapy: we are still looking for the efficacious drug. Ital J Pediatr. 2013;39:37. https://doi.org/10. 1186/1824-7288-39-37.

60. The World Health Organization Guidelines on Neonatal Seizures. 2011. http://apps.who.int/iris/bitstream/10665/77756/1/9789241548304_eng.pdf. Accessed 30 June 2018.

61. Glass HC, Kan J, Bonifacio SL, Ferriero DM. Neonatal seizures: treatment practices among term and preterm infants. Pediatr Neurol. 2012;46:111-5.

62. Pressler RM, Boylan GB, Marlow N, Blennow M, Chiron C, Cross JH, et al. NEonatal seizure treatment with medication off-patent (NEMO) consortium. Bumetanide for the treatment of seizures in newborn babies with hypoxic ischaemic encephalopathy (NEMO): an open-label, dose finding, and feasibility phase 1/2 trial. Lancet Neurol. 2015;14:469-77.

63. Painter MJ, Scher MS, Stein AD, Armatti S, Wang Z, Gardiner JC, et al. Phenobarbital compared with phenytoin for the treatment of neonatal seizures. N Engl J Med. 1999:341:485-9.

64. Furwentsches A, Bussmann C, Ramantani G, et al. Levetiracetam in the treatment of neonatal seizures: a pilot study. Seizure. 2010;19:185-9.

65. van Rooij LGM, Hellstrom-Westas L, de Vries LS. Treatment of neonatal seizures. Semin Fetal Neonatal Med. 2013;18:209-15.

66. Young TE, Mangum B. Neofax, A Manual of Drugs used in neonatal care CNS Drugs. 23rd ed. Montvale: Thomson Reuters; 2010. p. 232-3.

67. Loughnan PM, Greenwald A, Purton WW, Aranda JV, Watters G, Neims AH. Pharmacokinetic observations of phenytoin disposition in the newborn and young infant. Arch Dis Child. 1977;52:302-9.

68. Tulloch JK, Carr RR, Ensom MH. A systematic review of the pharmacokinetics of antiepileptic drugs in neonates with refractory seizures. J Pediatr Pharmacol Ther. 2012;17:31-44.

69. Merhar SL, Schibler KR, Sherwin CM, Meinzen-Derr J, Shi J, Balmakund T, Vinks AA. Pharmacokinetics of levetiracetam in neonates with seizures. J Pediatr. 2011;159:152-154.e3.

70. Ramantani G, Ikonomidou C, Walter B, Rating D, Dinger J. Levetiracetam: safety and efficacy in neonatal seizures. Eur J Paediatr Neurol. 2011;15(1):1-7.

71. Khan O, Cipriani C, Wright C, Crisp E, Kirmani B. Role of intravenous levetiracetam for acute seizure management in preterm neonates. Pediatr Neurol. 2013;49(5):340-3.

72. Kirmani BF. Levetiracetam-an alternative option in preterm neonates for acute seizure management. Mol Cell Epilepsy. 2014;1:e19.

73. Neininger MP, Ullmann M, Dahse AJ, Syrbe S, Bernhard MK, Frontini R, et al. Use of Levetiracetam in neonates in clinical practice: a retrospective study at a German university hospital. Neuropediatrics. 2015;46(5):329-34.

74. Han JY, Moon CJ, Youn YA, Sung IK, Lee IG. Efficacy of levetiracetam for neonatal seizures in preterm infants. BMC Pediatr. 2018;18:131.

75. Fitzgerald MP, Kessler SK, Abend NS. Early discontinuation of antiseizure medications in neonates with hypoxic-ischemic encephalopathy. Epilepsia. 2017;58(6):1047-53.

76. Natarajan N, Beatty CW, Gust J, Hamiwka L. Provider practices of phenobarbital discontinuation in neonatal seizures. J Child Neurol. 2018; 33(2):153-7.
77. Glass HC, Costarino AT, Stayer SA, Brett CM, Cladis F, Davis PJ. Outcomes for extremely premature infants. Anesth Analg. 2015;120:1337-51.

78. Ronen GM, Buckley D, Penney S, Streiner DL. Long-term prognosis in children with neonatal seizures: a population-based study. Neurology. 2007;69:1816-22.

79. Boylan GB, Pressler RM, Rennie JM, Morton M, Leow PL, Hughes R, et al. Outcome of electroclinical, electrographic, and clinical seizures in the newborn infant. Dev Med Child Neurol. 1999;41:819-25.

80. Pisani F, Cerminara C, Fusco C, Sisti L. Neonatal status epilepticus vs recurrent neonatal seizures: clinical findings and outcome. Neurology. 2007;69:2177-85.

81. Glass HC, Bonifacio SL, Peloquin S, Shimotake T, Sehring S, Sun Y, et al. Neurocritical care for neonates. Neurocrit Care. 2010;12:421-9.

82. Davis AS, Hintz SR, Van Meurs KP, Li L, Das A, Stoll BJ, et al. Seizures in extremely low birth weight infants are associated with adverse outcome. J Pediatr. 2010;157:720-5.e1-2.

83. Vohr BR, Wright LL, Dusick AM, Mele L, Verter J, Steichen JJ, et al. Neurodevelopmental and functional outcomes of extremely low birth weight infants in the National Institute of Child Health and Human Development neonatal research network, 1993-1994. Pediatrics. 2000;105(6):1216-26.

84. Murphy DJ, Hope PL, Johnson A. Neonatal risk factors for cerebral palsy in very preterm babies: case-control study. BMJ. 1997;314:404.
Ready to submit your research? Choose BMC and benefit from:

- fast, convenient online submission

- thorough peer review by experienced researchers in your field

- rapid publication on acceptance

- support for research data, including large and complex data types

- gold Open Access which fosters wider collaboration and increased citations

- maximum visibility for your research: over $100 \mathrm{M}$ website views per year

At BMC, research is always in progress.

Learn more biomedcentral.com/submissions 